\title{
EPIDEMIOLOGY OF OCULAR INJURY IN PAEDIATRIC POPULATION PRESENTING TO A TERTIARY HEALTH CENTRE
}

\author{
Somnath Das ${ }^{1}$, Sandip Samaddar², Parinita Singh ${ }^{3}$ \\ ${ }^{1}$ Associate Professor, Department of Ophthalmology, RIO, Medical College, Kolkata. \\ ${ }^{2}$ Assistant Professor, Department of Ophthalmology, RIO, Medical College, Kolkata. \\ ${ }^{3}$ Postgraduate Trainee, Department of Ophthalmology, RIO, Medical College, Kolkata.
}

\begin{abstract}
\section{BACKGROUND}

Ocular trauma is a worldwide cause of visual morbidity. It includes a spectrum of simple ocular surface foreign bodies, minute corneal abrasions to devastating perforating injuries causing blindness. Children are particularly susceptible to eye trauma. Identification of the cause of injuries among children may help in determining the most effective measures to prevent visual loss. The purpose of this study was to analyse the age and sex distribution, the type of ocular injury, causative agents, and visual status at the time of presentation.
\end{abstract}

\section{MATERIALS AND METHODS}

A total of 100 children (age 0-14 yrs.) who attended Outpatient Department and Emergency of Regional Institute of Ophthalmology, and got admitted were included in the study. Detailed history regarding mode and type of injury, time of injury and time elapsed to attend the hospital from the onset of injury noted. Visual status recoded. Detailed clinical examination done. Appropriate medical and surgical treatment given after assessing the type of injury according to the standard protocol.

\section{RESULTS}

Our study showed that male children (Male: Female 2.2:1) in the age group of 6 to 10 years (48\%) were affected most. Open globe injury was the commonest type (71\%). 44\% of children attended hospital 25 to 48 hours after the injury. Domestic injury with the wood stick was the commonest type. Majority of the children had visual acuity between 2/60 and PL+. 95 children required surgical intervention.

\section{CONCLUSION}

We have seen in our study that close supervision at home, school and play ground, public awareness and education regarding the hazardous nature of firecrackers, and road safety measures are critical to prevent the traumatic visual loss in children. Delay in presentation of children to the hospital may lead to substantial damage to the ocular structures during these initial crucial hours.

\section{KEYWORDS}

Paediatric Ocular Trauma, Type of Injury, Mode of Injury, Visual Acuity at Presentation, Traumatic Visual Loss.

HOW TO CITE THIS ARTICLE: Das S, Samaddar S, Singh P. Epidemiology of ocular injury in paediatric population presenting to a tertiary health centre. J. Evolution Med. Dent. Sci. 2017;6(55):4133-4137, DOI: 10.14260/Jemds/2017/895

\section{BACKGROUND}

Ocular trauma is a worldwide cause of visual morbidity. It includes a spectrum of simple ocular surface foreign bodies, minute corneal abrasions to devastating perforating injuries causing blindness. ${ }^{1,2}$ Children are particularly susceptible to eye trauma; $52 \%$ of all eye trauma affects paediatric patients and trauma is the leading cause of monocular blindness in children. ${ }^{3}$ Children younger than 5 years seem to be more affected, although other series indicate ages 11-15 years are at higher risk due to sport-related trauma particularly in economically developed countries with a male preponderance. In developing countries like India, domestic activities have a more significant role in injury occurrence. ${ }^{4,5}$

Financial or Other, Competing Interest: None.

Submission 04-05-2017, Peer Review 27-06-2017,

Acceptance 03-07-2017, Published 10-07-2017.

Corresponding Author:

Dr. Sandip Samaddar,

\#25, Sarat Chandra Road,

East Barisha,

Kolkata-700008.

E-mail: drsandipsamaddar@gmail.com

DOI: $10.14260 / j e m d s / 2017 / 895$

\section{(c) (1) $(9)$}

Injuries with sticks, stones, cricket ball, and metallic objects are the most common.6,7 Ocular injury occurs in three forms: open globe, closed globe, and adnexal injuries. Open globe injuries are one of the most common emergencies in Ophthalmology clinics and require immediate operation. ${ }^{6}$ Identification of the cause of injuries among children may help in determining the most effective measures to prevent visual loss. Work-related accidents are fairly common in developing countries where children work at a younger age or are bystanders. ${ }^{8}$ Paediatric ocular trauma has a significant impact on the future quality of life as children are exposed to a major risk of amblyopia. ${ }^{7}$

The Ocular Trauma Classification Group has developed a classification system ${ }^{9}$ based on BETT 10 and features of globe injury at initial examination (Birmingham Eye Trauma Terminology System). For evaluation, one has to ascertain quickly the extent of the injury, without risking further damage to the eye, and the need for further sub-specialist consultation.

A visual acuity should be attempted and documented if the child is verbal and conscious. Presence/absence of a relative APD is a very important neuro-ophthalmological sign. ${ }^{11,12}$ If the globe or eyelid are suspected to be lacerated, a shield should be placed on the eye, the patient should be kept 
nil per mouth. With any penetrating or lacerating injury to the eye or adnexa, tetanus immunisation status should be established and revaccination given if indicated. Appropriate radiologic studies should be obtained if orbital fracture, intraocular or intraorbital foreign body, or other intracranial injury is suspected. Chang and Rubin ${ }^{13,14}$ present a very thorough review of eyelid laceration injury and the proper approach to repair. Orbital bony fractures are one of the more commonly encountered findings in children who suffer head and face trauma. ${ }^{15-18}$ Grant et $\mathrm{al}^{16}$ and Egbert et al ${ }^{17}$ demonstrate that most of the orbital floor fractures in children are of the trapdoor type. Studies ${ }^{14-19}$ in the review period recommend surgical intervention within 5-7 days after the injury in children, versus 2 weeks or longer in adults.

Among paediatric ocular perforation, the most common manifestation was corneal tear. ${ }^{20} \mathrm{C}$ G Thompson Kumar, F A Billson and F Martin showed that the commonest causes of perforating ocular injury were sharp tools (knives/scissors) poked by the child into his/her own eye. ${ }^{21}$ Fireworks are responsible for $4.4 \%$ of all injuries and $80 \%$ of these are caused by bottle rockets. ${ }^{22}$ Studies ${ }^{14-19}$ in the review period recommend surgical intervention within 5-7 days after the injury in children, versus 2 weeks or longer in adults. Cranial nerve palsies, including third, fourth, and sixth nerves, often are found in conjunction with ocular and head trauma in children. ${ }^{23}$ The purpose of this study was to analyse the age and sex distribution, the type of ocular injury, causative agents, visual status at the time of presentation in paediatric ocular trauma at Regional Institute of Ophthalmology, Kolkata, West Bengal.

\section{MATERIALS AND METHODS}

A total of 100 children (Age 0-14 yrs.) who attended Outpatient Department and Emergency of Regional Institute of Ophthalmology, and got admitted were included in the study. Detailed history regarding mode and type of injury (Open or Closed type), time of injury and time elapsed to attend the hospital from the onset of injury noted. Visual status recoded with a Snellen acuity chart or a Rosenbaum near card. Detailed clinical examination using standard clinical and investigational procedure done. Closed globe injuries are zoned. Zone I injuries include superficial injuries of the bulbar conjunctiva, sclera, or cornea. Zone II injuries encompass damage to the lens apparatus or structures of the anterior segment. Zone III injuries include damage to the retina, vitreous, posterior uvea (e.g., ciliary body, choroid), and optic nerve. Pupillary reaction noted. Injuries due to chemical, electrical, or thermal agents were not included in this protocol.

This is an institution-based cross-sectional study. Statistical Analysis was performed with help of Epi Info (TM) 3.5.3 which is a trademark of the Centres for Disease Control and Prevention (CDC). Using this software, basic crosstabulation and frequency distributions were prepared.

Chi-square test was used to test the association between different study variables under study.

Corrected Chi-square test was used in case of any one of cell frequency was found less than 5 in the bivariate frequency distribution.

\section{RESULTS}

A total of 100 children (age 0-14 yrs.) who attended Outpatient Department and Emergency of Regional Institute of Ophthalmology, and got admitted were included in the study. The results of the study and the analysis are given below.

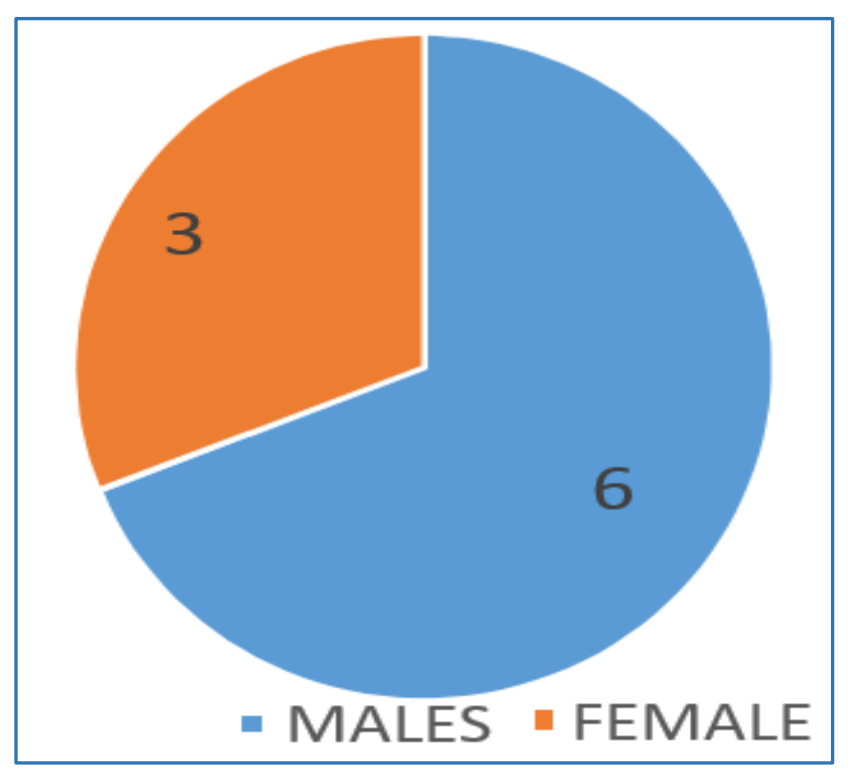

Figure 1. Sex Distribution

Out of 100 children there were $69 \%$ males and $31 \%$ females. The male: female ratio was 2.2:1.

\begin{tabular}{|c|c|}
\hline Age & Number of patients \\
\hline $0-5$ Yrs. & 33 \\
\hline 6-10 Yrs. & 48 \\
\hline 11-14 Yrs. & 19 \\
\hline \multicolumn{2}{|c|}{ Table 1. Age Distribution } \\
\hline
\end{tabular}

Majority of the children who suffered injury were of age group between 6-10 yrs., constituting $48 \%$ of the injuries. This was followed by age between $0-5$ yrs. which was $33 \%$. The age group between 11-14 yrs. had the least number of children amounting to $19 \%$.

\begin{tabular}{|c|c|}
\hline Type of Injury & Number of Patients \\
\hline Open Globe Injury & 71 \\
\hline Closed Globe Injury & 13 \\
\hline Adnexal Injury & 13 \\
\hline Chemical Injury & 03 \\
\hline \multicolumn{2}{|c|}{ Table 2. Type of Injury } \\
\hline
\end{tabular}

The injuries were classified as open globe, closed globe, adnexal and chemical injuries. $71 \%$ of the injuries were open globe followed by closed globe (13\%). Adnexal injuries constituted $13 \%$ of the injuries and $3 \%$ chemical injuries. 


\begin{tabular}{|c|c|}
\hline Causative Agents & Number of Patients \\
\hline Stick & 12 \\
\hline Brick/Stone & 06 \\
\hline Scissors/Knife & 12 \\
\hline Glass Piece & 06 \\
\hline Firecracker & 05 \\
\hline Finger nail & 05 \\
\hline Needle/Pin & 05 \\
\hline Ball & 05 \\
\hline Toy & 05 \\
\hline Scale & 04 \\
\hline Caterpillar Hair & 04 \\
\hline Pencil & 04 \\
\hline Lime Injury & 03 \\
\hline Bird Beak & 03 \\
\hline Iron Nail & 05 \\
\hline Others & 17 \\
\hline \multicolumn{2}{|c|}{ able 3. Causative Agents of Injury } \\
\hline \multicolumn{2}{|c|}{}
\end{tabular}

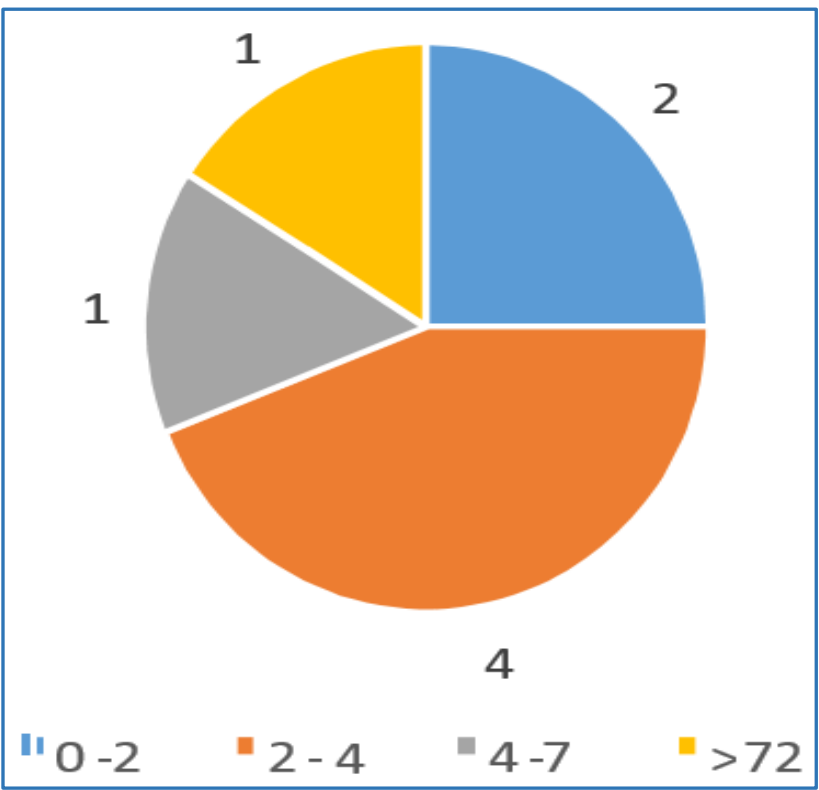

The most common mode of injury in these children was by stick, wooden stick was most commonly implicated followed by bamboo stick and jute stick. Out of the 12 injuries caused by stick, 10 were open globe type and 2 were closed globe type. 12 out of 100 injuries were due to scissors and knife. 10 of these were open globe injuries whereas 2 were adnexal injuries. 6 out of 100 injuries were caused by brick and stone; 3 of these injuries were open globe type, 2 were superficial foreign body and 1 was adnexal injury.

Another common mode of injury was by glass piece. 4 of these injuries were open globe type and 2 were adnexal injuries. Firecrackers caused 5 out of 100 injuries and all were open globe type. 5 injuries were due to ball and 4 out of these injuries were closed globe injuries. 4 of the children presented with closed globe injury due to caterpillar hair. Other modes of injury were needle, pin, scale, toys, bird beak, pencil, iron nail, goat or cow horn, hammer, blouse hook.

\begin{tabular}{|c|c|}
\hline Visual Acuity & Number of patients \\
\hline $6 / 6-6 / 12$ & 07 \\
\hline $6 / 18-6 / 36$ & 07 \\
\hline $6 / 60-3 / 60$ & 17 \\
\hline $2 / 60-\mathrm{PL}+$ & 37 \\
\hline NO PL & 05 \\
\hline Couldn't be assessed & 27 \\
\hline \multicolumn{2}{|c|}{ Table 4. Visual Acuity at Presentation } \\
\hline
\end{tabular}

$37 \%$ of the children who presented to us had visual acuity between 2/60 and PL (Perception of light) + . In 27\% of the children, the visual acuity couldn't be assessed as many a times younger children don't cooperate. $17 \%$ had visual acuity between $6 / 60-3 / 60$. $7 \%$ of the patients had vision between $6 / 18-6 / 36$. Another $7 \%$ had vision between $6 / 6$ $6 / 12$. PL was denied in $5 \%$ patients.

\section{Figure 2. Time Interval between the Time of Injury to Hospitalisation}

Majority (44\%) of the children who suffered ocular trauma presented to our hospital between 25-48 hrs. of injury, $15 \%$ presented between $49-72$ hrs. and $16 \%$ presented after $72 \mathrm{hrs}$. Only $25 \%$ of the patients presented within the first $24 \mathrm{hrs}$. I also noted that majority of the injuries occurred during the day while playing unsupervised. Most of the injuries occurred at or near home.

\begin{tabular}{|c|c|}
\hline Time & Number of Patients \\
\hline $0-24 \mathrm{hrs}$. & 88 \\
\hline$>24 \mathrm{hrs}$. & 7 \\
\hline \multicolumn{2}{|c|}{ Table 5. Time Interval between } \\
Hospitalisation and Surgery \\
\hline
\end{tabular}

\section{Conservative Management 5}

88 out 100 patients who were hospitalised were operated within the first 24 hours. 7 patients were operated after 24 hours and 5 did not require surgery. Out of the 5 patients who were conservatively managed, 3 were chemical injury patients and 2 were closed globe injuries presenting with hyphaema.

\section{DISCUSSION}

Children with immature motor skill and their tendency to imitate adult behaviour without evaluating risks is an important mode of injury (Thordarson pelting, civilian unrest 2010, U, Ragnasson AT et al). ${ }^{7}$ Serious ocular trauma gives rise to irrevocable structural damage or functional loss which imposes an enduring burden throughout the most productive years of life (Robert JC). ${ }^{8}$

In our study, out of 100 children, there were $69 \%$ males and $31 \%$ females. The male: female ratio was 2.2:1. Our results were consistent with a study conducted in Rajendra Prasad Centre for Ophthalmic Sciences by Saxena R et al. ${ }^{24}$ Out of 204 children aged fourteen years or less, there were $133(65.1 \%)$ boys and $71(34.9 \%)$ girls. 
Another study, Pattern of Paediatric Ocular Trauma in Hayatabad Medical Complex, Peshawar by Tariq Farooq Babar et $\mathrm{al}^{25}$ found male to female ratio as 3.3:1. In our study, we have found that majority of the children who suffered injury were of age group between 6-10 yrs. (48\%). This was followed by age between $0-5$ yrs. (33\%). The age group between 11-14 yrs. had the least number of children (19\%). This result was consistent with the study of Pattern of Paediatric Ocular Trauma in Hayatabad Medical Complex, Peshawar by Tariq Farooq Babar et al. In our study, 71\% of the injuries were open globe followed by closed globe (13\%). Adnexal injuries constituted $13 \%$ of the injuries and $3 \%$ chemical injuries. In a study conducted in Rajendra Prasad Centre for Ophthalmic Sciences, by Saxena R et al 214 children aged 14 years or less presenting to the emergency with ocular injury were included. Majority of injuries occurred in children of 5 years and older (87.7\%). Closed globe injuries being $42.2 \%$, open globe injuries $53.9 \%$ and $3.9 \%$ were chemical injuries. In our study, we only included the children who required hospitalisation; therefore, the number of open globe injuries was much more as compared to other injuries.

The most common mode of injury in these children was by stick (12\%), injury by household items like scissors and knife $(12 \%)$. Others were glass piece $(6 \%)$, firecracker $(5 \%)$, finger nail (5\%), needle/pin (5\%), ball (5\%), toy (5\%), scale (4\%), caterpillar hair (4\%), pencil (4\%), bird beak (3\%), iron nail (5\%), all the chemical injuries were due to lime (3\%). Few other modes of injuries were due to goat or cow horn, hammer, blouse hook, etc. Sports related objects like bat, ball, hockey result in injuries in 10 patients $(6.53 \%)$, firecrackers result in 2 patients (1.30\%). Majority (75\%) of the children who suffered ocular trauma presented to our hospital after $24 \mathrm{hrs}$. of injury. Only $25 \%$ of the patients presented within the first 24 hrs. In a study conducted in Rajendra Prasad Centre for Ophthalmic Sciences, by Saxena R et al, 49 (24\%) cases presented within 6 hours of injury while 70 (34.3\%) presented after more than 24 hours after trauma. Major reasons for delayed presentation to our hospital were poor communication and lack of awareness amongst parents about the seriousness of ocular injuries. We noted that $3 \%$ of the patients who presented with endophthalmitis had presented after 72 hrs. of injury. 88 out 100 patients who were hospitalised were operated within the first 24 hours. There was a delay of more than $24 \mathrm{hrs}$. in 7 out of 100 cases, the delays occurred due to unavailability of anaesthetist which was the another limiting factor.

\section{CONCLUSION}

The most common aspect of paediatric ocular trauma is prevention. Our study points to male children of school going age as the high-risk group and the outdoor activities as the high-risk sites for ocular injuries.

We have seen in our study that close supervision at home, school and play ground, public awareness and education regarding the hazardous nature of firecrackers, and road safety measures are critical to prevent the traumatic visual loss in children. Legislation to ban the use of firecrackers by children would help in saving many eyes. Delay in presentation of children to the hospital may lead to substantial damage to the ocular structures during these initial crucial hours. Improvement of rural health services is very much needed and it is important to provide them with facilities and equipment necessary for urgent management of ocular trauma.

\section{REFERENCES}

[1] Desai P, MacEwen CJ, Baines P, et al. Incidence of cases of ocular trauma admitted to hospital and incidence of blinding outcome. Br J Ophthalmol 1996;80(7):592-6.

[2] Ngo CS, Leo SW. Industrial accident-related ocular emergencies in a tertiary hospital in Singapore. Singapore Med J 2008;49(4):280-5.

[3] Jandeck C, Kellner U, Bornfeld N, et al. Open globe injuries in children. Graefes Arch Clin Exp Ophthalmol 2000;238(5):420-6.

[4] Oiticica-Barbosa MM, Kasahara N. Eye trauma in children and adolescents: perspectives from a developing country and validation of the ocular trauma score. J Trop Pediatr 2015;61(4):238-43.

[5] Chakraborti C, Giri D, Choudhury KP, et al. Paediatric ocular trauma in a tertiary eye care center in Eastern India. Indian J Public Health 2014;58(4):278-80.

[6] MacEwen CJ. Ocular injuries. J R Coll Surg Edinb 1999;44(5):317-23.

[7] Ervin-Mulvey LD, Nelson LB, Freeley DA. Pediatric eye trauma. Pediatr Clin North Am 1983;30(6):1167-83.

[8] Umeh RE, Umeh OC. Causes and visual outcome of childhood eye injuries in Nigeria. Eye (Lond) 1997;11(Pt 4):489-95.

[9] Pieramici DJ, Sternberg P, Aaberg TM, et al. A system for classifying mechanical injuries of the eye (globe). The ocular trauma classification group. Am J Ophthalmol 1997;123(6):820-31.

[10] Kuhn F, Morris R, Witherspoon CD, et al. A standardized classification of ocular trauma. Ophthalmology 1996;103(2):240-3.

[11] De Juan E, Sternberg P, Michels RG. Penetrating ocular injuries. Types of injuries and visual results. Ophthalmology 1983;90(11):1318-22.

[12] Joseph E, Zak R, Smith S, et al. Predictors of blinding or serious eye injury in blunt trauma. J Trauma 1992;33(1):19-24.

[13] Chang EL, Rubin PA. Management of complex eyelid lacerations. Int Ophthalmol Clin 2002;42(3):187-201.

[14] Hogg NJ, Horswell BB. Soft tissue pediatric facial trauma: a review. J Can Dent Assoc 2006;72(6):54952.

[15] Kwon JH, Moon JH, Kwon MS, et al. The differences of blowout fractures of the inferior orbital wall between children and adults. Arch Otolaryngol Head Neck Surg 2005;131(8):723-7.

[16] Grant JH 3rd, Patrinely JR, Weiss AH, et al. Trapdoor fracture of the orbit in a pediatric population. Plast Reconstr Surg 2002;109(2):482-9.

[17] Egbert JE, May K, Kersten RC, et al. Pediatric orbital floor fracture: direct extraocular muscle involvement. Ophthalmology 2000;107(10):1875-9.

[18] Bansagi ZC, Meyer DR. Internal orbital fractures in the pediatric age group: characterization and management. Ophthalmology 2000;107(5):829-36.

[19] Burnstine MA. Clinical recommendations for repair of isolated orbital floor fractures: an evidence-based analysis. Ophthalmology 2002;109(7):1207-10. 
[20] Krishnan M, Sreenivasan R. Ocular injuries in union territory of Pondicherry-clinical presentation. Indian J Ophthalmol 1988;36(2):82-5.

[21] Brophy M, Sinclair SA, Hostetler SG, et al. Pediatric eye injury- related hospitalizations in the United States. Pediatrics 2006;117(6):e1263-71.

[22] Kuhn FC, Morris RC, Witherspoon CD, et al. Serious fireworks- related eye injuries. Ophthalmic Epidemiol 2000;7(2):139-48.
[23] Holmes JM, Mutyala S, Maus TL, et al. Pediatric third, fourth, and sixth nerve palsies: a population-based study. Am J Ophthalmol 1999;127(4):388-92.

[24] Saxena R, Sinha R, Purohit A, et al. Rajendra Prasad centre for ophthalmic sciences, all India institute of medical sciences, New Delhi, India. Indian J Pediatrics 2002;69(10):863-7.

[25] Babar TF, Jan S, Gul L, et al. Pattern of paediatric ocular trauma in Hayatabad medical complex, Peshawar. Pak J Med Res 2006;45:6-9. 